\title{
Article \\ Diversity and Risk Factors Associated with Multidrug and Methicillin-Resistant Staphylococci Isolated from Cats Admitted to a Veterinary Clinic in Eastern Province, Saudi Arabia
}

\author{
Ahmed Elmoslemany ${ }^{1,+}\left(\mathbb{D}\right.$, Ibrahim Elsohaby $2,3, *,+\left(\mathbb{D}\right.$, Mohammed Alorabi ${ }^{4}$, Mohamed Alkafafy ${ }^{4}(\mathbb{D}$, \\ Theeb Al-Marri ${ }^{5}$, Ali Aldoweriej ${ }^{6}$, Fanan A. Alaq1 ${ }^{7}$, Abdullah Almubarak ${ }^{5}$ and Mahmoud Fayez ${ }^{5,8,+}$ (D)
}

check for updates

Citation: Elmoslemany, A.; Elsohaby, I.; Alorabi, M.; Alkafafy, M.; Al-Marri, T.; Aldoweriej, A.; Alaql, F.A.; Almubarak, A.; Fayez, M. Diversity and Risk Factors Associated with Multidrug and Methicillin-Resistant Staphylococci Isolated from Cats Admitted to a Veterinary Clinic in Eastern Province, Saudi Arabia. Antibiotics 2021, 10, 367. https:// doi.org/10.3390/antibiotics10040367

Academic Editors: John Barlow and Laura Selva Martínez

Received: 5 March 2021

Accepted: 29 March 2021

Published: 31 March 2021

Publisher's Note: MDPI stays neutral with regard to jurisdictional claims in published maps and institutional affiliations.

Copyright: (c) 2021 by the authors. Licensee MDPI, Basel, Switzerland. This article is an open access article distributed under the terms and conditions of the Creative Commons Attribution (CC BY) license (https:/ / creativecommons.org/licenses/by/ $4.0 /)$.
1 Hygiene and Preventive Medicine Department, Faculty of Veterinary Medicine, Kafrelsheikh University, Kafr El-Sheikh 33516, Egypt; aelmoslemany@gmail.com

2 Department of Animal Medicine, Faculty of Veterinary Medicine, Zagazig University, Zagazig City 44511, Egypt

3 Department of Health Management, Atlantic Veterinary College, University of Prince Edward Island, Charlottetown, PE C1A 4P3, Canada

4 Department of Biotechnology, College of Science, Taif University, P.O. Box 11099, Taif 21944, Saudi Arabia; maorabi@tu.edu.sa (M.A.); m.kafafy@tu.edu.sa (M.A.)

5 Al-Ahsa Veterinary Diagnostic Lab, Ministry of Environment, Water and Agriculture, Al-Ahsa 31982, Saudi Arabia; theep8@hotmail.com (T.A.-M.); Abd-20151@hotmail.com (A.A.); mahmoudfayez30@hotmail.com (M.F.)

6 Veterinary Health and Monitoring, Ministry of Environment, Water and Agriculture, Riyadh 11195, Saudi Arabia; Dr.alivet@mewa.gov.sa

7 Department of Microbiology, College of Science, King Saud University, Riyadh 11451, Saudi Arabia; fanan.abdulaziz@gmail.com

8 Department of Bacteriology, Veterinary Serum and Vaccine Research Institute, Ministry of Agriculture, Cairo 131, Egypt

* Correspondence: ielsohaby@upei.ca; Tel.: +1-902-566-6063

+ These authors contributed equally to this work.

\begin{abstract}
Understanding the distribution, antimicrobial resistance (AMR), and risk factors associated with multidrug-resistant (MDR) and methicillin-resistant staphylococci (MRS) isolated from cats admitted to veterinary clinics may decrease the risk of MDR and MRS transmission to humans and other cats. As such, the objectives of this study were to investigate the diversity in Staphylococcus spp. recovered from different anatomical locations in healthy and diseased cats and to determine the occurrence of MDR and MRS spp. as well as possible risk factors associated with colonization in these cats. Five swabs were collected from the anus, skin, ear canal, conjunctival sac, and nares of each cat (209 healthy and 191 diseased) admitted to a veterinary clinic in Eastern Province, Saudi Arabia, between January and December 2018. Prior to sample collection, cat owners completed a questionnaire collecting information on cat demographics, health status, management, and antimicrobial usage. In total, 179 Staphylococcus isolates were recovered from healthy $(n=71)$ and diseased $(n=108)$ cats, including 94 (52.5\%) coagulase-positive staphylococci (CoPS), and 85 (47.5\%) coagulase-negative staphylococci (CoNS). Five Staphylococcus spp. were identified, namely, Staphylococcus aureus, Staphylococcus pseudintermedius, Staphylococcus felis, Staphylococcus capitis, and Staphylococcus saprophyticus. Staphylococcus isolates were most commonly resistant to penicillin $(56.4 \%)$ and ciprofloxacin $(25.7 \%)$; however, no isolate was resistant to clindamycin. Thirty (16.8\%) Staphylococcus spp. (24 S. aureus and 6 S. pseudintermedius) isolates were MDR, with resistance to up to six different antibiotic classes. Only 17 (9.5\%) Staphylococcus spp. (15 methicillin-resistant S. aureus and 2 methicillin-resistant S. pseudintermedius) harbored the mecA gene. Risk factor analysis showed that cats with a history of antibiotic therapy, those raised mainly indoors with a child, and those who visit a veterinary clinic for treatment were at higher risk of MDR and MRS colonization. In conclusion, MDR and MRS were common in healthy and diseased cats in Saudi Arabia. Thus, an effective antimicrobial stewardship program and further studies using a One Health approach are required to investigate the role of cats as vectors for AMR transmission to humans.
\end{abstract}


Keywords: antimicrobial resistance; Staphylococcus; cats; methicillin-resistance; multidrug resistance; risk factors

\section{Introduction}

Staphylococci are opportunistic bacteria that may colonize the skin, mucous membrane of the nasal cavity, conjunctival sac, throat, and anus [1,2]. Staphylococci are currently categorized on the basis of their ability to produce coagulase: coagulase-positive staphylococci (CoPS) or coagulase-negative staphylococci (CoNS). Staphylococcus aureus and Staphylococcus pseudintermedius are the most prevalent CoPS spp. isolated from humans and animals [3]. Numerous CoNS spp. have been isolated, such as Staphylococcus saprophyticus, Staphylococcus capitis, Staphylococcus haemolyticus, and Staphylococcus felis [4]. CoPS spp. have higher pathogenic potential than CoNS spp. [4,5]; this may be attributed to the association between CoNS spp. and both chronic and subacute infections [5]. Furthermore, CoNS spp. are less frequently involved in community-associated diseases but are one of the major nosocomial pathogens that impact human health $[4,6]$.

In humans and animals, staphylococcal infections are generally treatable with topical or systemic antimicrobials [7]. However, the worldwide spread of antimicrobial resistance makes treatment with antimicrobial agents difficult [3]. In terms of antimicrobial resistance, methicillin-resistant staphylococci (MRS) are of particular importance because they are resistant to all the $\beta$-lactams antibiotics commonly used in animals and humans and thus have a major impact on public health [8,9].

Household pets, such as dogs and cats share a common environment with their owners and are treated with antimicrobial agents similar to those prescribed to humans. The close contact between pets and owners allows the transmission of zoonotic bacteria either directly through contact or indirectly through contamination of food and the environment [10]. Therefore, household pets are considered potential reservoirs of antimicrobial resistant zoonotic bacteria, such as methicillin-resistant $S$. aureus (MRSA), methicillin-resistant S. pseudintermedius (MRSP), and extended-spectrum $\beta$-lactamase- producing Escherichia coli [11-13]. Several studies have reported that the majority of MRSA found in pets originates from humans, either pet owners or veterinarians [3,14]; however, veterinarians are at higher risk of MRSA infection than pet owners [15]. Another study attributed pets as an occasional source of MRSA infection in pet owners [16]. Thus, it seems that MRSA can be transmitted between animals and humans in a bi-directional manner [17].

Information regarding antimicrobial use in household pets, risk factors, and transmission routes of antimicrobial resistant bacteria between humans and household pets is scarce [18]. Several studies have reported infections related to MRSA in dogs and cats $[3,19,20]$. Nonetheless, few studies have investigated the staphylococci populations in healthy cats, as well as infections due to MRSP and methicillin-resistant CoNS species in cats $[17,21]$. In Saudi Arabia, a large number of studies have focused on MRSA infection in farm animals, including cattle [22], goats [23], and camels [24]; however, to the author's knowledge, no studies have investigated the diversity and multidrug resistance (MDR) of both CoPS and CoNS spp. in healthy and diseased cats. Therefore, this study aimed to (1) investigate the diversity in Staphylococcus spp. recovered from different anatomical locations in healthy and diseased cats; (2) determine the occurrence of MDR and MRS spp. recovered from healthy and diseased cats; and (3) determine the possible risk factors associated with colonization of MDR and MRS spp. recovered from healthy and diseased cats in Eastern Province, Saudi Arabia.

\section{Results}

2.1. Study Population

Between January and December 2018, a total of 2000 swabs were collected from 400 cats admitted to a veterinary clinic in Eastern Province, Saudi Arabia. The study 
population was $43.3 \%(173 / 400)$ male and $56.7 \%(227 / 400)$ female. The breeds of cats included in the study were Persian $(n=162)$, Siamese $(n=112)$, Himalayan $(n=59)$, Birman $(n=53)$, Egyptian Mau $(n=10)$, and Arabian Mau $(n=4)$. Most cats were admitted for vaccination and/or grooming $(209 / 400)$, but other reasons for admission included clinical examination due to digestive distress $(81 / 400)$, respiratory distress $(39 / 400)$, eye discharge (59/400), ear discharge (61/400), and skin wound and/or abscess $(64 / 400)$.

\subsection{Staphylococcus spp. Distribution}

Out of the 400 cats, Staphylococcus isolates were recovered from $153(38.3 \%)$ cats, including $61(29.2 \%)$ healthy and $92(48.2 \%)$ diseased cats. In total, 179 Staphylococcus isolates were recovered from healthy $(71 / 179)$ and diseased $(108 / 179)$ cats (Figure 1). Out of the 179 isolates, 94 (52.5\%) were CoPS and 85 (47.5\%) were CoNS. On the basis of $16 \mathrm{~S}$ rRNA, five Staphylococcus spp. were identified, namely, S. aureus, S. pseudintermedius, S. felis, S. capitis, and S. saprophyticus, with GenBank accession numbers MK123464, MK123481, MK123404, MK127538 and MK127551, respectively. CoPS isolates included 75 (79.8\%) S. aureus and $19(20.2 \%)$ S. pseudintermedius, whereas CoNS isolates included 55 (64.7\%) S. felis, $13(15.3 \%)$ S. capitis and $17(20.0 \%)$ S. saprophyticus (Figure 1). The distribution of Staphylococcus spp. based on anatomical locations in healthy and diseased cats is presented in Table 1. There are no significant differences in distribution of Staphylococcus spp. between diseased and healthy cats $(p=0.833)$, cat sex $(p=0.893)$ and breeds $(p=0.844)$.

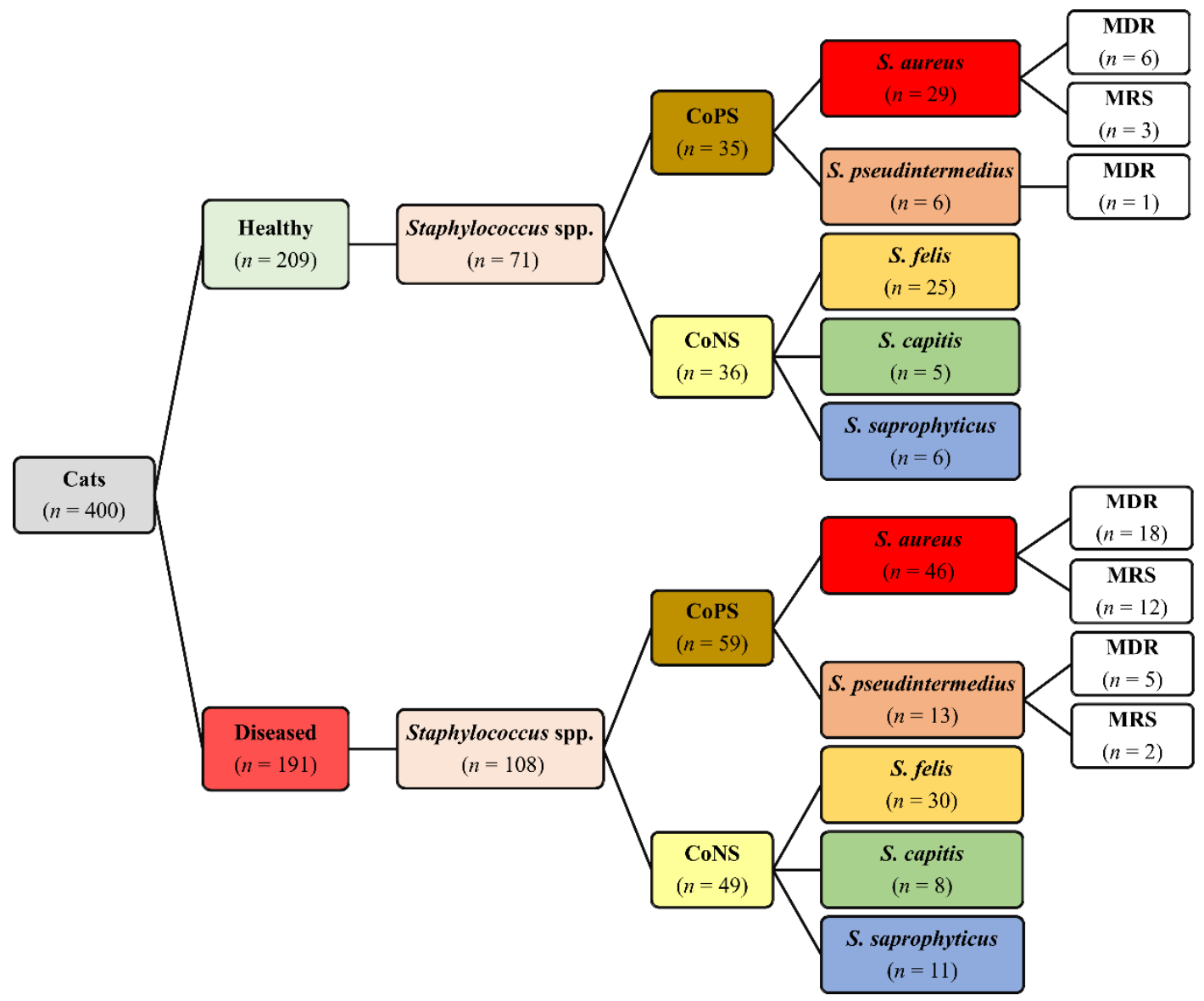

Figure 1. Distribution of Staphylococcus spp., multidrug resistance (MDR) and methicillin-resistant staphylococci (MRS) isolated from 400 healthy and diseased cats admitted to a veterinary clinic in Eastern Province, Saudi Arabia. 
Table 1. Number of Staphylococcus spp. isolated from 400 healthy and diseased cats admitted to a veterinary clinic in Eastern Province, Saudi Arabia.

\begin{tabular}{|c|c|c|c|c|c|c|}
\hline \multirow{2}{*}{$\begin{array}{l}\text { Anatomical } \\
\text { Locations }\end{array}$} & \multirow{2}{*}{$\begin{array}{c}\text { No. of } \\
\text { Isolates(\%) }\end{array}$} & \multicolumn{2}{|c|}{$\begin{array}{l}\text { No. (\%) of Coagulase-Positive } \\
\text { Staphylococci }\end{array}$} & \multicolumn{3}{|c|}{ No. $(\%)$ of Coagulase-Negative Staphylococci } \\
\hline & & S. aureus & S. pseudintermedius & S. felis & S. capitis & S. saprophyticus \\
\hline & & \multicolumn{5}{|c|}{ I-Healthy Cats $(n=209)$} \\
\hline Anus & $7(3.4)$ & $2(28.6)$ & $0(0.0)$ & $1(14.3)$ & $1(14.3)$ & $3(42.9)$ \\
\hline Skin & $28(13.4)$ & $10(35.7)$ & $2(7.1)$ & $13(46.4)$ & $2(7.1)$ & $1(3.6)$ \\
\hline Ear canal & $15(7.2)$ & $5(33.3)$ & $2(13.3)$ & $4(26.7)$ & $2(13.3)$ & $2(13.3)$ \\
\hline Conjunctival sac & $14(6.7)$ & $7(50.0)$ & $1(7.1)$ & $6(42.9)$ & $0(0.0)$ & $0(0.0)$ \\
\hline Nares & $7(3.4)$ & $5(71.4)$ & $1(14.3)$ & $1(14.3)$ & $0(0.0)$ & $0(0.0)$ \\
\hline \multirow[t]{2}{*}{ Total } & $71(34.0)$ & $29(40.8)$ & $6(8.5)$ & $25(35.2)$ & $5(7.0)$ & $6(8.5)$ \\
\hline & & \multicolumn{5}{|c|}{ II-Diseased Cats $(n=191)$} \\
\hline Anus & $13(6.8)$ & $3(23.1)$ & $1(7.7)$ & $3(23.1)$ & $2(15.4)$ & $4(30.8)$ \\
\hline Skin & $45(23.6)$ & $19(42.2)$ & $5(11.1)$ & $13(28.9)$ & $4(8.9)$ & $4(8.9)$ \\
\hline Ear canal & $25(13.1)$ & $11(44.0)$ & $2(8.0)$ & $8(32.0)$ & $2(8.0)$ & $2(8.0)$ \\
\hline Conjunctival sac & $14(7.3)$ & $6(42.9)$ & $3(21.4)$ & $4(28.6)$ & $0(0.0)$ & $1(7.1)$ \\
\hline Nares & $11(5.8)$ & $7(63.6)$ & $2(18.2)$ & $2(18.2)$ & $0(0.0)$ & $0(0.0)$ \\
\hline Total & $108(56.5)$ & $46(42.6)$ & $13(12.0)$ & $30(27.8)$ & $8(7.4)$ & $11(10.2)$ \\
\hline
\end{tabular}

\subsection{Antimicrobial Susceptibility}

The antimicrobial susceptibility test showed that $56.4 \%$ of Staphylococcus isolates were resistant to penicillin (PEN), and 25.7\% were resistant to ciprofloxacin (CIP); however, no isolate was resistant to clindamycin (CLI). The rates of resistance to amikacin (AMK), tetracycline (TET), trimethoprim/sulfamethoxazole (SXT), gentamicin (GEN), and amoxicillin clavulanic acid (AMC) were 17.3\%, 16.8\%, 16.2\%, 14.0\% and $12.8 \%$, respectively, and $9.5 \%, 8.9 \%$, and $7.8 \%$ of Staphylococcus isolates showed resistance to cefoxitin (FOX), chloramphenicol (CHL), and erythromycin (ERY), respectively.

The antimicrobial resistance patterns of all Staphylococcus spp. isolated from healthy cats were slightly different than those isolated from diseased cats except for $S$. aureus (Figure 2). The frequency of isolates resistant to AMC (odds ratio (OR): $3.6,95 \%$ confidence interval (CI): 1.2-11.0) and CIP (OR: 3.6, 95\% CI: 1.6-8.1) were significantly greater in diseased cats than in healthy cats; however, there were no differences $(p>0.05)$ between diseased and healthy cats for the other antimicrobials. Figure 3 shows the antimicrobial resistance patterns of CoPS and CoNS isolates recovered from the different anatomical locations in healthy and diseased cats. 
Species $\square$ S. aureus $\square$ S. pseudintermedius $\square$ S. felis $\square$ S. capitis $\square$ S. saprophyticus

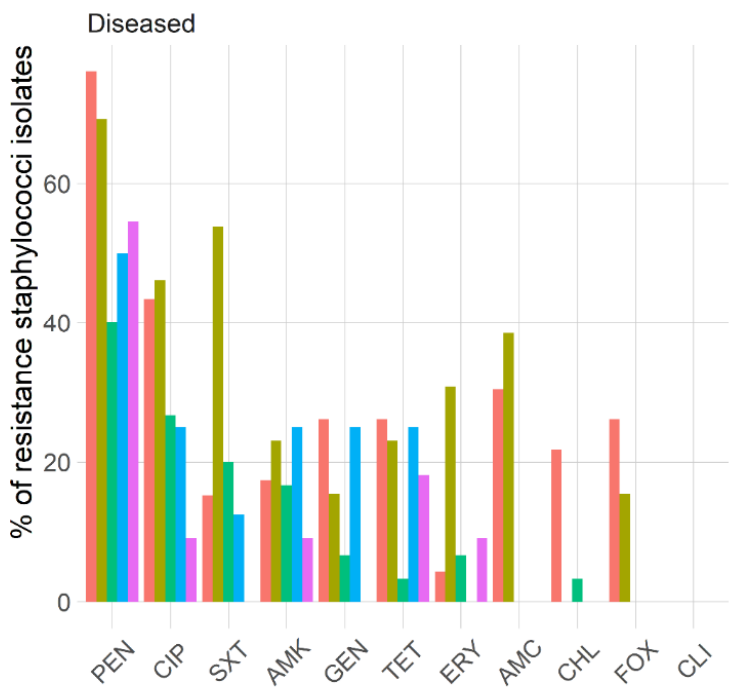

Healthy

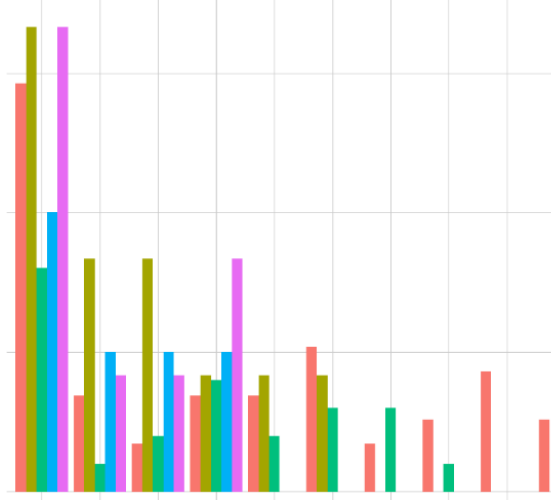

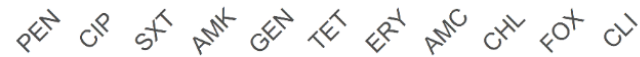

Antimicrobials

Figure 2. Frequency of antimicrobial resistance of Staphylococcus spp. recoverd from healthy and diseased cats.

(a)

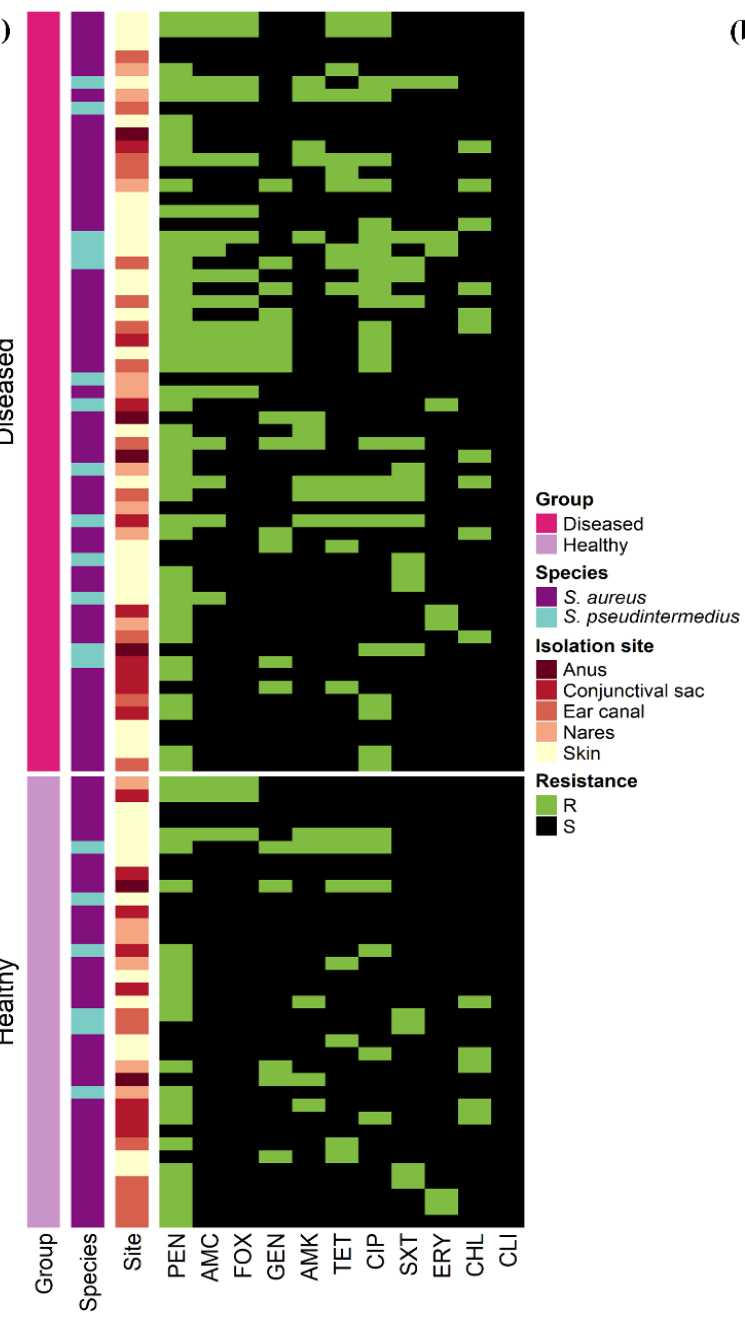

(b)

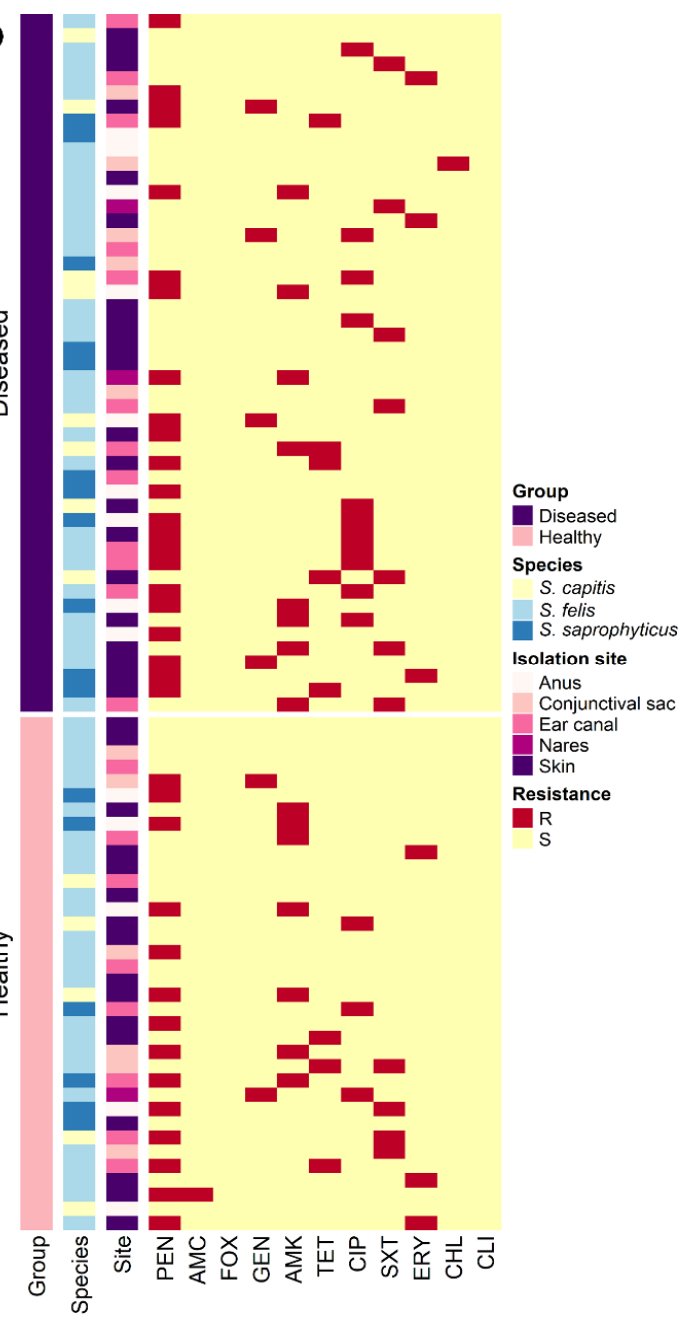

Figure 3. Heat map representation of the antimicrobial resistance patterns of (a) 94 coagulase-positive and (b) 85 coagulasenegative staphylococci isolates recovered from 400 healthy and diseased cats admitted to a veterinary clinic in Eastern Province, Saudi Arabia. 
The mean multiple antibiotic resistance (MAR) index for Staphylococcus isolates was 0.22 , ranging from 0.09 to 0.64 . The highest MAR index (0.64) was found in S. aureus and S. pseudintermedius isolated from the skin of diseased cats. Most of the isolates (58.7\%) showed a MAR index $<0.2$. Variation in the MAR index of Staphylococcus spp. recovered from healthy and diseased cats is demonstrated in Figure 4. There was a significant $(p=0.003)$ difference in the MAR index of $S$. aureus recovered from healthy and diseased cats; however, there was no difference in the MAR index of S. pseudintermedius, S. felis, $S$. capitis and $S$. saprophyticus recovered from healthy and diseased cats.

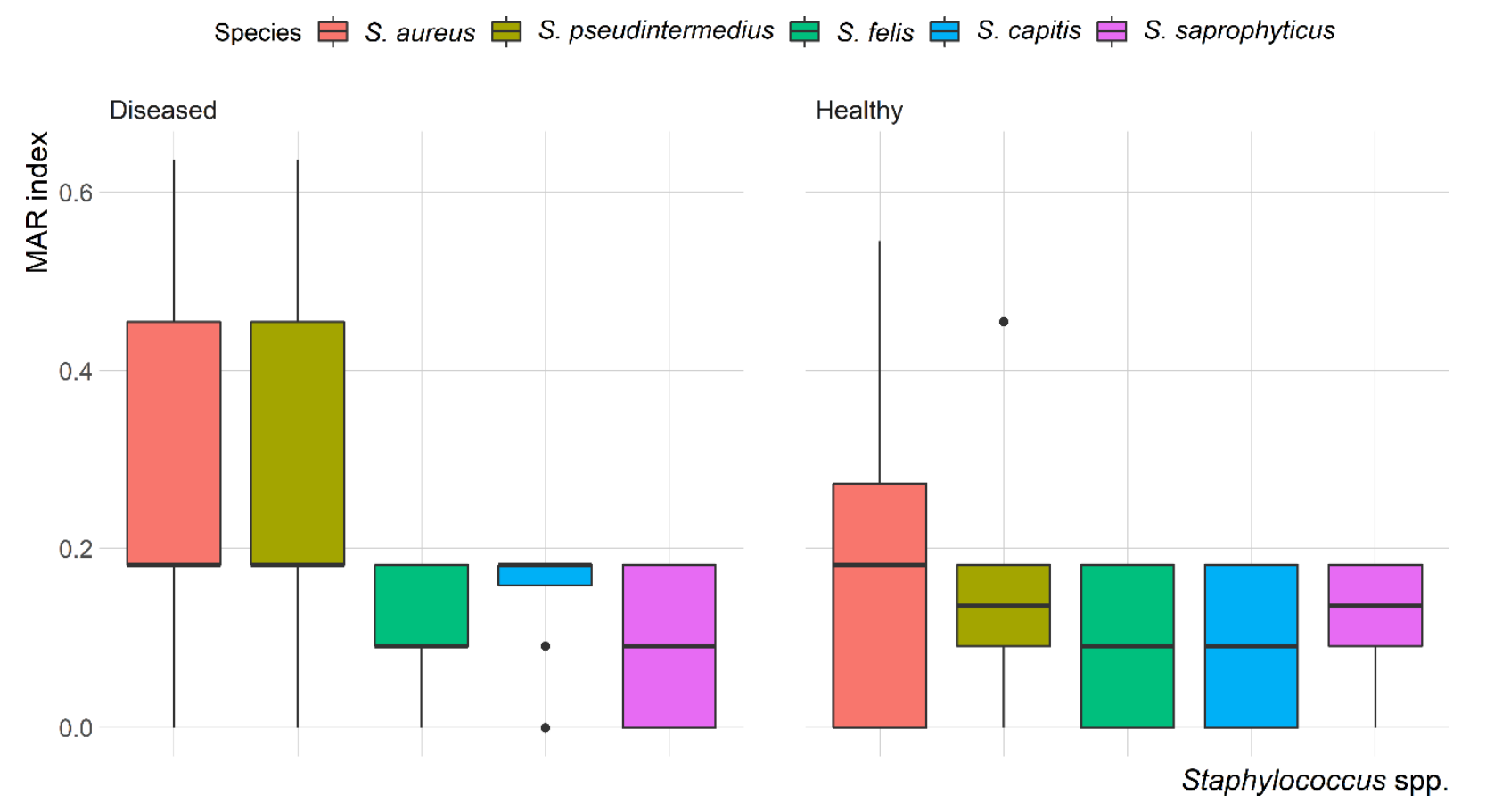

Figure 4. Box and whisker plot of multiple antibiotic resistance (MAR) index among Staphylococcus spp. recovered from different anatomical locations in healthy and diseased cats.

Non-metric multidimensional scaling (NMDS) plots demonstrated all Staphylococcus isolates (Figure 5a); within each Staphylococcus spp. (Figure 5b-f), isolates clustered according to the cat group (healthy/diseased) based on their antimicrobial resistance profiles (resistant/sensitive). Staphylococcus spp. isolated from healthy and diseased cats had similar antimicrobial profiles, but there were no significant differences between $S$. aureus isolates recovered from different anatomical locations in diseased cats. 

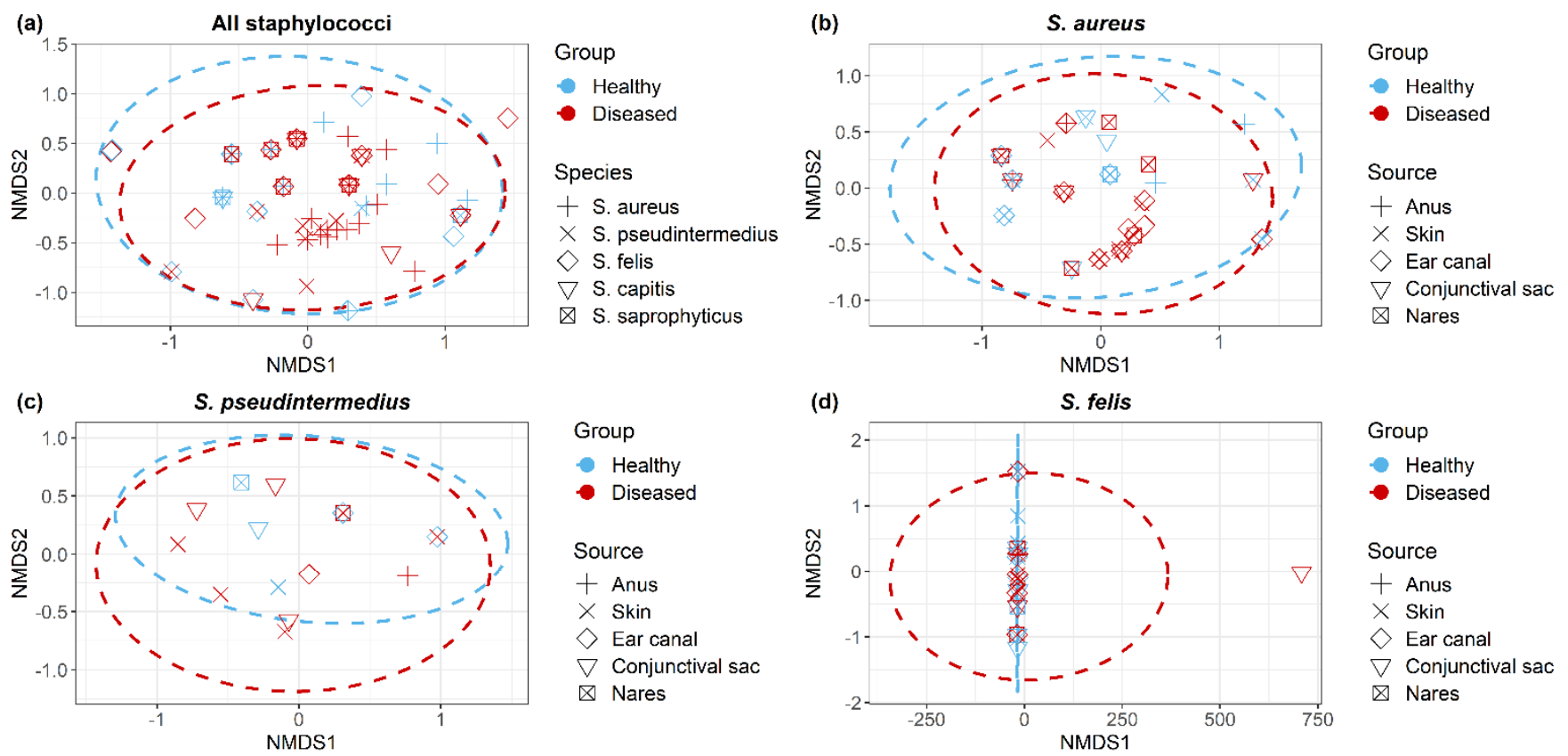

Group

- Healthy

- Diseased

Source

+ Anus

$\times$ Skin

$\diamond$ Ear canal

$\nabla$ Conjunctival sac

$\triangle$ Nares
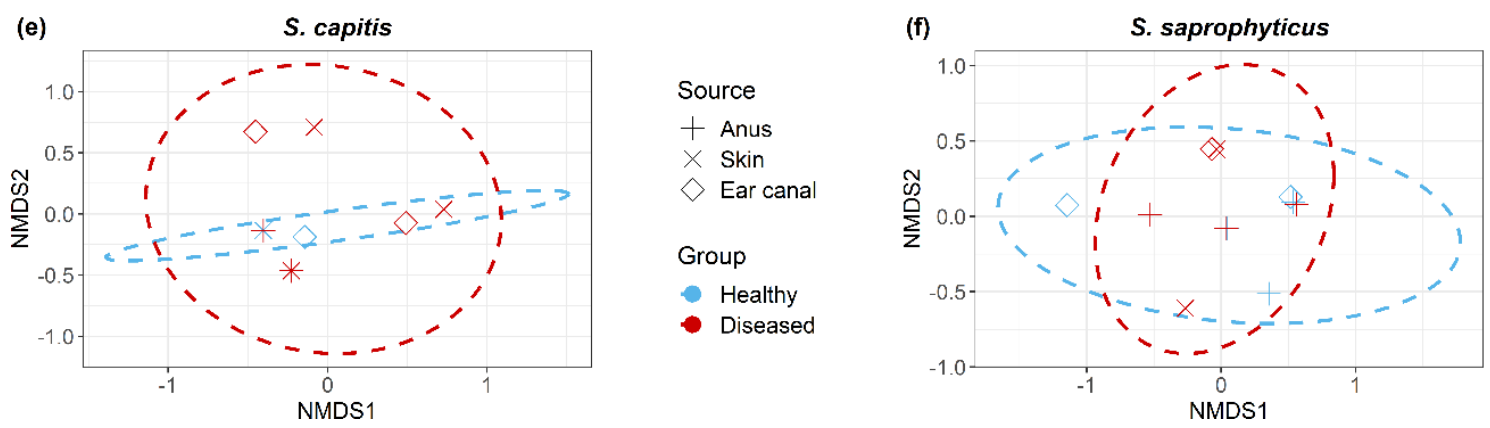

Source

+ Anus

$\times$ Skin

$\diamond$ Ear canal

$\times$ Skin

$\diamond$ Ear canal

Group

- Healthy

- Diseased

Group

- Healthy

- Diseased

Figure 5. Non-metric multidimensional scaling ordination (NMDS) of antimicrobial resistant Staphylococcus isolates (a) across all Staphylococcus spp., (b) S. aureus, (c) S. pseudintermedius, (d) S. felis, (e) S. capitis and (f) S. saprophyticus. Dotted lines indicate clustering of isolates corresponds to cat group.

\subsection{MDR and MRS Isolates}

Thirty (16.8\%) Staphylococcus spp. (24 S. aureus and 6 S. pseudintermedius) were MDR isolates (Table 2), with resistance to up to six different antibiotic classes. The minimum inhibitory concentration of a representative number of MDR Staphylococcus spp. isolates are presented in Supplementary Table S1. In total, 17 (9.5\%) Staphylococcus spp. (15 MRSA and 2 MRSP) were resistant to FOX, OXA and harbored the mecA gene (Table 2). Fourteen $(82.4 \%)$ MRS isolates were recovered from diseased cats, and only three (17.6\%) MRS isolates were recovered from healthy cats (Table 3). No MRSP isolates were found in healthy cats. MRSA ST 80 and ST5 were the most prevalent isolates in healthy and diseased cats, respectively. On the other hand, MRSP ST71 was the only MRSP sequence type detected in any cats. The $P V L$ genes (lukS-PV and $l u k F-P V)$ were detected in four $(26.7 \%)$ MRSA isolates. 
Table 2. Number of multidrug resistance (MDR) and methicillin-resistant staphylococci (MRS) isolates recovered from healthy and diseased cats admitted to a veterinary clinic in Eastern Province, Saudi Arabia.

\begin{tabular}{|c|c|c|c|c|c|c|c|}
\hline \multirow{2}{*}{ Staphylococcus spp. } & \multirow{2}{*}{$n$} & \multicolumn{2}{|c|}{ No. of MDR } & \multirow{2}{*}{ Total } & \multicolumn{2}{|c|}{ No. of MRS } & \multirow{2}{*}{ Total } \\
\hline & & Healthy & Diseased & & Healthy & Diseased & \\
\hline Coagulase positive & 94 & $7 / 35$ & $23 / 59$ & $30 / 94$ & $3 / 35$ & $14 / 59$ & $17 / 94$ \\
\hline S. aureus & 75 & $6 / 29$ & $18 / 46$ & $24 / 75$ & $3 / 29$ & $12 / 46$ & $15 / 75$ \\
\hline S. pseudintermedius & 19 & $1 / 6$ & $5 / 13$ & $6 / 19$ & $0 / 6$ & $2 / 13$ & $2 / 19$ \\
\hline Coagulase negative & 85 & $0 / 36$ & $0 / 49$ & $0 / 85$ & $0 / 36$ & $0 / 49$ & $0 / 85$ \\
\hline S. felis & 55 & $0 / 25$ & $0 / 30$ & $0 / 55$ & $0 / 25$ & $0 / 30$ & $0 / 55$ \\
\hline S. capitis & 13 & $0 / 5$ & $0 / 8$ & $0 / 13$ & $0 / 5$ & $0 / 8$ & $0 / 13$ \\
\hline S. saprophyticus & 17 & $0 / 6$ & $0 / 11$ & $0 / 17$ & $0 / 6$ & $0 / 11$ & $0 / 17$ \\
\hline Total & 179 & $7 / 71$ & $23 / 108$ & $30 / 179$ & $3 / 71$ & $14 / 108$ & $17 / 179$ \\
\hline
\end{tabular}

Table 3. Multilocus sequence typing (MLST) and antimicrobial resistance patterns of methicillin-resistant S. aureus (MRSA) and S. pseudintermedius (MRSP) isolates recovered from healthy and diseased cats admitted to a veterinary clinic in Eastern Province, Saudi Arabia.

\begin{tabular}{|c|c|c|c|c|c|c|c|c|}
\hline \multirow{2}{*}{ Cat ID } & \multirow{2}{*}{ Group } & \multirow{2}{*}{$\begin{array}{l}\text { Anatomical } \\
\text { Locations }\end{array}$} & \multirow{2}{*}{ Species } & \multirow{2}{*}{$\begin{array}{l}\text { Sequence } \\
\text { Type }\end{array}$} & \multicolumn{2}{|c|}{ Genotype $^{1}$} & \multirow{2}{*}{$\begin{array}{c}\text { Antimicrobial Resistance } \\
\text { Patterns }\end{array}$} & \multirow{2}{*}{ MAR $^{2}$} \\
\hline & & & & & lukS & lukF & & \\
\hline 3 & Healthy & Nares & MRSA & 80 & + & + & PEN, AMC, FOX & 0.27 \\
\hline 5 & Healthy & $\begin{array}{l}\text { Conjunctival } \\
\text { sac }\end{array}$ & MRSA & 80 & + & + & PEN, AMC, FOX & 0.27 \\
\hline 15 & Diseased & Skin & MRSA & 22 & - & - & PEN, AMC, FOX, TET, CIP & 0.45 \\
\hline 16 & Diseased & Skin & MRSA & 22 & - & - & PEN, AMC, FOX, TET, CIP & 0.45 \\
\hline 34 & Healthy & Skin & MRSA & 239 & - & - & $\begin{array}{l}\text { PEN, AMC, FOX, AMK, } \\
\text { TET, CIP }\end{array}$ & 0.55 \\
\hline 40 & Diseased & Nares & MRSA & 239 & - & - & $\begin{array}{c}\text { PEN, AMC, FOX, AMK, } \\
\text { TET, CIP }\end{array}$ & 0.55 \\
\hline 57 & Diseased & Ear canal & MRSA & 239 & - & - & $\begin{array}{c}\text { PEN, AMC, FOX, AMK, } \\
\text { TET, CIP }\end{array}$ & 0.55 \\
\hline 70 & Diseased & Skin & MRSA & 80 & + & + & PEN, AMC, FOX & 0.27 \\
\hline 92 & Diseased & Skin & MRSA & 8 & - & - & PEN, AMC, FOX, CIP, SXT & 0.45 \\
\hline 102 & Diseased & Ear canal & MRSA & 8 & - & - & PEN, AMC, FOX, CIP, SXT & 0.45 \\
\hline 109 & Diseased & Ear canal & MRSA & 5 & - & - & $\begin{array}{c}\text { PEN, AMC, FOX, GEN, CIP, } \\
\text { CHL }\end{array}$ & 0.55 \\
\hline 118 & Diseased & $\begin{array}{c}\text { Conjunctival } \\
\text { sac }\end{array}$ & MRSA & 5 & - & - & PEN, AMC, FOX, GEN, CIP & 0.45 \\
\hline 125 & Diseased & Skin & MRSA & 5 & - & - & PEN, AMC, FOX, GEN, CIP & 0.45 \\
\hline 133 & Diseased & Ear canal & MRSA & 5 & - & - & PEN, AMC, FOX, GEN, CIP & 0.45 \\
\hline 139 & Diseased & Nares & MRSA & 80 & + & + & PEN, AMC, FOX & 0.27 \\
\hline 27 & Diseased & Skin & MRSP & 71 & - & - & $\begin{array}{c}\text { PEN, AMC, OXA, AMK, } \\
\text { CIP, SXT, ERY }\end{array}$ & 0.64 \\
\hline 82 & Diseased & Skin & MRSP & 71 & - & - & $\begin{array}{l}\text { PEN, AMC, OXA, AMK, } \\
\text { CIP, SXT, ERY }\end{array}$ & 0.64 \\
\hline
\end{tabular}

${ }^{1}+=$ PVL genes positive; $-=$ PVL genes negative; $-=$ not tested. ${ }^{2}$ MAR = multiple antibiotic resistance index.

\subsection{Risk Factors}

Table 4 shows the univariable association $(p<0.25)$ between independent variables and each of the dependent variables (MDR and MRS). Both MDR and MRS were positively associated with a number of family characteristics, namely, the use of antibiotic therapy, the presence of acne, hospitalization of a family member, and having a child at home, in addition to previous and recent antibiotic therapy for the cat and visiting a veterinary clinic for treatment rather than vaccination. On the other hand, cats living partially indoors and outdoors had a lower risk of MDR and MRS compared with indoors living cats. 
Table 4. Univariable analysis of risk factors associated with multidrug resistance (MDR) and methicillin-resistant staphylococci (MRS) isolates recovered from 400 healthy and diseased cats admitted to a veterinary clinic in Eastern Province, Saudi Arabia.

\begin{tabular}{|c|c|c|c|c|}
\hline \multirow{2}{*}{ Factors } & \multicolumn{2}{|c|}{ MDR } & \multicolumn{2}{|c|}{ MRS } \\
\hline & Odds Ratio & $p$-Value & Odds Ratio & $p$-Value \\
\hline \multicolumn{5}{|l|}{ Family use antimicrobials } \\
\hline No & 1.00 (ref.) & & 1.00 (ref.) & \\
\hline Yes & 6.0 & 0.000 & 18.2 & 0.000 \\
\hline \multicolumn{5}{|l|}{ Family member with acne } \\
\hline No & 1.00 (ref.) & & 1.00 (ref.) & \\
\hline Yes & 3.0 & 0.004 & 20.4 & 0.000 \\
\hline \multicolumn{5}{|l|}{ Hospitalization } \\
\hline No & 1.00 (ref.) & & 1.00 (ref.) & \\
\hline Yes & 4.6 & 0.000 & 8.3 & 0.000 \\
\hline \multicolumn{5}{|l|}{ Previous antimicrobial use for cat } \\
\hline No & 1.00 (ref.) & & 1.00 (ref.) & \\
\hline Yes & 5.5 & 0.000 & 7.4 & 0.002 \\
\hline \multicolumn{5}{|c|}{ Type of previously used antimicrobials } \\
\hline Non & 1.00 (ref.) & 0.000 & 1.00 (ref.) & 0.000 \\
\hline Cefalexin & 4.4 & 0.006 & 3.6 & 0.121 \\
\hline Ampicillin & 10.2 & 0.001 & 24.1 & 0.000 \\
\hline Amoxicillin & 2.8 & 0.223 & 6.5 & 0.045 \\
\hline \multicolumn{5}{|l|}{ Current antimicrobials use for cat } \\
\hline No & 1.00 (ref.) & & 1.00 (ref.) & \\
\hline Yes & 12.2 & 0.000 & 29.1 & 0.000 \\
\hline \multicolumn{5}{|l|}{ Child at home } \\
\hline No & 1.00 (ref.) & & 1.00 (ref.) & \\
\hline Yes & 3.8 & 0.003 & 3.6 & 0.017 \\
\hline \multicolumn{5}{|l|}{ Cat living } \\
\hline Indoors & 1.00 (ref.) & 0.008 & 1.00 (ref.) & 0.005 \\
\hline Indoors-outdoors & 0.3 & 0.002 & 0.2 & 0.002 \\
\hline \multicolumn{5}{|l|}{ Family living } \\
\hline Urban & 1.00 (ref.) & 0.012 & 1.00 (ref.) & 0.091 \\
\hline Countryside & 0.2 & 0.043 & 0.2 & 0.138 \\
\hline Apartment & 0.3 & 0.016 & 0.4 & 0.142 \\
\hline \multicolumn{5}{|l|}{ Reason being at clinic } \\
\hline Vaccination and/or grooming & 1.00 (ref.) & & 1.00 (ref.) & \\
\hline Treatment & 4.0 & 0.002 & 5.4 & 0.009 \\
\hline \multicolumn{5}{|l|}{ Cat care } \\
\hline Adult male & 1.00 (ref.) & 0.012 & 1.00 (ref.) & 0.003 \\
\hline Adult female & 0.3 & 0.002 & 0.1 & 0.003 \\
\hline Child & 0.4 & 0.313 & 0.5 & 0.530 \\
\hline All family & 0.3 & 0.057 & 0.1 & 0.043 \\
\hline
\end{tabular}

Table 5 shows the final multivariable logistic regression model for factors associated with MDR and MRS. The odds of MDR were approximately 9 and 6 times higher when the antimicrobial was previously used as treatment for the family and cat, respectively. The cat's family having a child at home was also associated with higher odds of MDR (OR = 4.3). The odds of MDR were 3.6 times higher if the purpose of the veterinary clinic visit were to receive treatment rather than vaccination or grooming. Finally, indoor-outdoor cats had lower odds of MDR (OR = 0.3) compared with indoor-only cats. The model for MRS produced a similar set of predictors as the MDR model; this model also showed a higher risk $(\mathrm{OR}=15.9)$ of MRS when a family member had acne. 
Table 5. Multivariable logistic regression analysis of risk factors associated with multidrug resistance (MDR) and methicillin-resistant staphylococci (MRS) isolates recovered from 400 healthy and diseased cats admitted to a veterinary clinic in Eastern Province, Saudi Arabia.

\begin{tabular}{|c|c|c|c|c|}
\hline \multirow{2}{*}{ Factors } & \multicolumn{2}{|c|}{ MDR } & \multicolumn{2}{|c|}{ MRS } \\
\hline & OR $(95 \% \text { CI })^{1}$ & $p$-Value & OR $(95 \% \text { CI })^{1}$ & $p$-Value \\
\hline \multicolumn{5}{|l|}{ Family use antimicrobials } \\
\hline No & 1.00 (ref.) & & 1.00 (ref.) & \\
\hline Yes & $8.8(3.47-22.30)$ & 0.000 & $11.9(2.48-57.46)$ & 0.002 \\
\hline \multicolumn{5}{|l|}{ Family member with acne } \\
\hline No & - & - & 1.00 (ref.) & \\
\hline Yes & - & - & $15.9(2.64-95.45)$ & 0.003 \\
\hline \multicolumn{5}{|c|}{ Previous antimicrobial use for cat } \\
\hline No & 1.00 (ref.) & & 1.00 (ref.) & \\
\hline Yes & $6.1(2.21-16.60)$ & 0.000 & $12.4(2.56-59.67)$ & 0.034 \\
\hline \multicolumn{5}{|l|}{ Child at home } \\
\hline No & 1.00 (ref.) & & 1.00 (ref.) & \\
\hline Yes & $4.3(1.63-11.54)$ & 0.003 & $6.9(1.46-32.43)$ & 0.015 \\
\hline \multicolumn{5}{|l|}{ Cat living } \\
\hline Indoors & 1.00 (ref.) & & 1.00 (ref.) & \\
\hline Indoors-outdoors & $0.29(0.12-0.69)$ & 0.006 & $0.15(0.04-0.65)$ & 0.011 \\
\hline \multicolumn{5}{|l|}{ Reason being at clinic } \\
\hline Vaccination and/or grooming & 1.00 (ref.) & & 1.00 (ref.) & \\
\hline Treatment & $3.6(1.34-9.61)$ & 0.011 & $5.4(1.14-25.88)$ & 0.034 \\
\hline _cons & $\begin{array}{c}0.001 \\
(0.000-0.010)\end{array}$ & 0.000 & $\begin{array}{c}0.00 \\
(0.000-0.000)\end{array}$ & 0.000 \\
\hline
\end{tabular}

${ }^{1}$ OR: odds ratio; CI: confidence interval.

\section{Discussion}

\subsection{Staphylococcus spp. Distribution}

This study demonstrated that many healthy cats $(29.2 \%)$ are carriers of Staphylococcus spp.; this proportion was higher in diseased cats $(48.2 \%)$. Similar studies have reported that Staphylococcus spp. are more frequently isolated in diseased cats than in healthy cats $[25,26]$. In this study, Staphylococcus spp. was recovered from various anatomical locations, including the skin, anus, conjunctival sac, ear canal, and nares, which is consistent with previous reports $[27,28]$. This distribution is common as Staphylococcus spp. are among the normal bacterial flora of various body sites.

In this study, CoPS spp. were isolated more often than CoNS spp.; however, other studies have reported CoNS spp. to be the most prevalent Staphylococcus in cats and dogs admitted to veterinary clinics in Canada and South Korea [28-30]. In this study, $S$. aureus was the most frequently identified Staphylococcus spp. in both healthy and diseased cats, followed by $S$. felis; this is in disagreement with previously published studies [26,31,32], which reported CoNS as the most frequently occurring species in healthy and diseased cats. S. aureus is part of the normal bacterial flora in cats, especially those who are kept in close contact with their owners, which may explain the high occurrence of S. aureus in this study [33]. Furthermore, S. aureus is thought to be involved in $<5 \%$ of skin infections [29,34,35], but in this work, 38.7\% (29/75) of S. aureus isolates were recovered from skin swabs. Other studies have reported S. felis [30] and S. pseudintermedius [31,36] as the most common Staphylococcus spp. in cats, regardless of their health.

\subsection{Antimicrobial Susceptibility}

The antimicrobial susceptibility test demonstrated the effectiveness of different antimicrobial agents, including CLI, FOX, CHL, and ERY, and identified the best initial choices for the treatment of Staphylococcus infection in diseased and healthy cats; the results of this susceptibility test confirmed the results previous studies [31,32]. In the present work, a high proportion of Staphylococcus isolates were resistant to PEN (56.4\%) and CIP (25.7\%). Results 
from other countries show wide variation in Staphylococcus resistance patterns, but PEN and CIP are generally less effective for treating Staphylococcus infections in cats [19,31,32]. The Staphylococcus isolates recovered from diseased cats were resistant to more antimicrobial agents than those recovered from healthy cats, with significant differences in resistance to AMC and CIP. Resistance to these agents, which are used extensively in veterinary clinics, has been reported to be common among staphylococci from diseased cats $[37,38]$.

In this study, MDR Staphylococcus isolates were recovered from healthy and diseased cats. Thirty $(16.8 \%)$ of the isolates were resistant to more than three antimicrobial classes; however, only 17 of the MDR isolates were associated with the presence of the mecA gene (MRS). This result is similar to that of Gandolfi-Decristophoris et al. [19], who reported that MDR was not always associated with the presence of the mecA gene. Interestingly, resistance to PEN, AMC, FOX, and CIP was associated with MRS isolates; this association is relevant and may reflect the higher exposure of MRS isolates to these agents. The high rates of MRS isolate resistance to PEN, AMC, FOX, and CIP is alarming as they are the key antimicrobials used for the decolonization of MRSA [4].

The MRSA isolates recovered in this study were linked to one clonal complex (CC8; ST 8 and 239) and three singleton clones (ST80, 22 and 5). MRSA-ST80 has emerged as an important pathogen in community and hospital infections in many Middle Eastern countries. In Saudi Arabia, two studies reported the same proportions of MRSA-ST80 in nasal carriage and infections in hospitals $[39,40]$. The ability of MRSA-ST80 to disseminate in the community has been reported [41,42]. Furthermore, the transmission of MRSA-ST80 among different host species in the context of households and veterinary practices has been described by Drougka et al. [41], who reported that dogs and cats can be reservoir of MRSA-ST80, causing severe infection in humans. In Saudi Arabia, the pandemic Vienna/Hungarian/Brazilian clone (CC8/ST239-III) and its variants continue to circulate in Dammam and Riyadh [43]. Furthermore, the hospital-associated MRSA-ST239-III was the prevalent clone detected in most of the studies performed in Saudi Arabia between 2001 and 2013 [44]. The pediatric clone (CC5) has also identified in rare cases in Saudi Arabian hospitals [44]. Results obtained from this study showed that only four MRSA isolates were $P V L$ gene positive. The $P V L$ gene is considered as a stable genetic marker for community-associated MRSA [45] and has been associated with necrotic skin lesions and community-acquired necrotic pneumonia [46].

\subsection{Risk Factors}

The identification of risk factors for MDR and MRS staphylococci colonization in pets is essential to controlling infection and transmission between humans and animals. Cats carrying MRSA represent a potential risk to human health because close contact between cats and owners can facilitate pathogen transfer. In this study, cats visiting the veterinary clinic for treatment had a higher risk of MDR and MRS compared with those visiting the veterinary clinic for vaccination and/or grooming. Similar results have been reported for MRSA [15] and MRS [32] in dogs and cats. Additionally, previous antibiotics treatment, for either the cat or family members, was associated with a higher risk of MDR and MRS. Other studies have also identified previous antimicrobial therapy as a risk factor for the development of colonization by MRS [33,47].

Antibiotic therapy may support MRS colonization by suppressing other competing bacterial infections. There was a positive association between MDR or MRS and the presence of a child at home. Compared with adult, children are more likely to handle animals extensively and touch their faces or mouths, which increase the risk of disease transmission. A recent study on community-associated MRSA in children showed that pets whose primary caretaker was MRSA colonized were more likely to be MRSA colonized than pets whose primary caretaker was not MRSA-colonized (50\% vs. 4\%) [48]. Cats living indoors showed a higher risk of MDR or MRS than those living indoors-outdoors. This association between indoor living and increased risk of MDR or MRS may be due to the increased close contact between humans and cats in indoor settings or related to 
indoor cats being more commonly located in urban areas, with greater access to veterinary care and, consequently, more antibiotic prescriptions. The reason for the veterinary clinic visit was a risk factor for MDR and MRS colonization, which is in accordance with the results obtained from previous studies [32,47,49]. Like previous studies, we did not find a significant association between MDR and MRS colonization and the cat's sex, breed, or type of diet [50].

\subsection{Limitations}

It should be noted that our study has limitations. The study design, including sampling and risk factor assessment at a single point in time, cannot be used to establish a temporal relationship between MDR or MRS and the different risk factors; however, our results provide baseline information for control measures as well as for the design of future studies. Cat owners reported all the risk factors in the study, so recall bias may affect the information that was provided; it likely had a minimal impact, and we do not consider this bias to be significant.

\section{Materials and Methods}

\subsection{Study Population and Animals}

The study was conducted between January and December 2018 and included 400 cats admitted to a veterinary clinic in Eastern Province, Saudi Arabia. Cats included in the study were divided into two groups based on the reason for their visit to the clinic: (a) healthy cats $(n=209)$ included apparently healthy cats that were admitted to the clinic for vaccination and/or grooming; (b) diseased cats $(n=191)$ included cats that were admitted for clinical examination and had one or more of the following clinical signs: conjunctivitis, otitis, diarrhea, skin wound, abscess, and/or respiratory signs. Cat recruitment was on a voluntary basis. Cat owners were asked to provide a written informed consent prior to their cats being sampled.

\subsection{Sample and Data Collection}

Five swabs were collected from the anus, skin, ear canal, conjunctival sac, and nares of each cat. In total, 2000 swabs were collected by professional veterinarians conducted in accordance with the Local Ethics Committee for animal research in Saudi Arabia. Each swab was kept in a sterile tube containing $2 \mathrm{~mL}$ of liquid brain-heart infusion broth (BHI: Difco) and then transported cooled at $4{ }^{\circ} \mathrm{C}$ to the laboratory for later analysis. Prior to sample collection, owners completed a questionnaire collecting information about demographics, health status, management, and antimicrobial usage; this information is presented in Supplementary Table S2.

\subsection{Staphylococcus spp. Isolation}

Tubes containing swabs and $2 \mathrm{~mL}$ of BHI were incubated aerobically at $37^{\circ} \mathrm{C}$ for $18 \mathrm{~h}$. A $10 \mu \mathrm{L}$ aliquot of the broth was streaked onto Baird-Parker agar supplemented with egg yolk tellurite, mannitol salt agar, and blood agar (Oxoid, Basingstoke, Hampshire, UK) and then incubated aerobically at $37^{\circ} \mathrm{C}$ for $24 \mathrm{~h}$. Morphologically typical staphylococcal colonies were purified on 5\% sheep blood agar and verified by Gram staining, plus a coagulase and catalase test. Biochemically identified Staphylococcus isolates were defined to the species level with the VITEK ${ }^{\circledR} 2$ COMPACT system (bioMerieux, Marcy l'Etoile, France) using Gram-positive cards, following manufacturer guidelines. Presumptively identified staphylococcal colonies were stored in $40 \%$ glycerol saline at $-70{ }^{\circ} \mathrm{C}$ for further investigation.

\subsection{Staphylococcus spp. Identification}

According to manufacturer guidelines, genetic DNA from Staphylococcus isolates was extracted from an overnight culture using the QIAamp DNA mini kit (Qiagen SA, Courtaboeuf, France). Extracted DNA was subjected to PCR using primers specific for 
Staphylococcus 16S rRNA and reaction conditions described by Jaffe et al. [51]. The PCR products were verified on $1.5 \%$ agarose gel and then sequenced using Genetic Analyzer 3500 (Applied Biosystems, Foster City, CA, USA). The 16S rRNA sequences were compared with sequences deposited in the GenBank database using the BLAST algorithm. Identification of Staphylococcus spp. was deemed reliable if sequence similarities with reference genes were $>98 \%$.

\subsection{Antimicrobial Susceptibility Testing}

The antimicrobial susceptibility of Staphylococcus isolates was determined using the disk diffusion method. Eleven different antimicrobial agents that are widely used for companion animals in Saudi Arabia were tested: penicillin (PEN: 10 units), amoxicillin clavulanic acid (AMC: 20/10 $\mu \mathrm{g}$ ), cefoxitin (FOX: $30 \mu \mathrm{g}$ ), gentamicin (GEN: $10 \mu \mathrm{g}$ ), amikacin (AMK: $30 \mu \mathrm{g}$ ), tetracycline (TET: $30 \mu \mathrm{g}$ ), ciprofloxacin (CIP: $5 \mu \mathrm{g}$ ), trimethoprim/sulfamethoxazole (SXT: $1.25 / 23.75 \mu \mathrm{g}$ ), erythromycin (ERY: $15 \mu \mathrm{g}$ ), chloramphenicol (CHL: $30 \mu \mathrm{g})$, and clindamycin (CLI: $2 \mu \mathrm{g})$. These antimicrobial agents were purchased from Oxoid (Basingstoke, Hampshire, UK). Results were interpreted according to the Clinical and Laboratory Standards Institute (CLSI) [52] and European Committee on Antimicrobial Susceptibility Testing (EUCAST) guidelines for antimicrobial susceptibility tests [53]. Staphylococcus aureus reference strain ATCC 29737 was included in each run to assess the reliability of the method. MDR was defined as resistance to at least three antimicrobial agents belonging to three different antibiotic classes [54]. The multiple antibiotic resistance (MAR) index was calculated as the ratio of the number of antibiotics to which the isolate displayed resistance to the number of antibiotics to which the isolate had been evaluated for susceptibility [55].

\subsection{MRS spp. Identification}

The standard disk diffusion method was used to screen all Staphylococcus isolates for phenotypic methicillin resistance. The antimicrobial agent FOX (30 $\mu \mathrm{g})$ and oxacillin (OXA: $1 \mu \mathrm{g}$ ) was used as described by CLSI [52]. Staphylococcus isolates that showed phenotypic resistance to FOX and OXA were investigated for the presence of the mecA gene, encoding methicillin resistance, using PCR, as described previously by Murakami et al. [56]. Multilocus sequence typing (MLST) of mecA-positive isolates was performed as previously described $[57,58]$. The sequence type (ST) and allelic profile of methicillinresistant isolates (MRSA and MRSP) were assigned by comparing the database on the MLST website (https: / / pubmlst.org/, accessed on 30 March 2021). MRSA isolates were also screened for the presence of the virulence gene Panton-Valentine leucocidin $(P V L)$. Two different alleles of the $P V L$ genes $l u k S-P V$ and $l u k F-P V$, were investigated according to the method described by Otokunefor et al. [59].

\subsection{Data Analysis}

Data were visualized with $\mathrm{R}$ software ( $\mathrm{R}$ Core Team, 2019; version 3.5.3). The $\mathrm{R}$ package "Complex-Heatmap" was used to build a heatmap based on the antimicrobial resistance profiles of each isolate [60]. Associations between Staphylococcus spp. isolates and cat condition (healthy vs. diseased), sex, and breeds were assessed using the Chisquare and Fisher's Exact tests. Non-metric multidimensional scaling (NMDS) [61] was performed using the metaMDS function of the vegan package to compare the dissimilarity of antimicrobial resistance profiles, using the Bray-Curtis distance between isolates across all Staphylococcus spp. and within each species. Permutational multivariate analysis of variance (PERMANOVA) [62] was employed using the adonis function of the vegan package to test whether the Staphylococcus isolates recovered from different anatomical locations in healthy and diseased cats had equivalent antimicrobial resistance profiles. $p$-values for PERMANOVA test statistics (F) were obtained using 999 permutations.

The association between the dependent variables $(1-\operatorname{MDR}(1=$ yes vs. $0=$ no), 2 -MRS, $(1=$ yes vs. $0=$ no) $)$ and each of the independent variables (Table S1) was 
assessed using univariable logistic regression analyses. All variables with a $p<0.25$ in the initial univariable analysis were checked for multicollinearity using Spearman's rank-order correlation statistics. The final multivariable logistic model was built using backward stepwise elimination at $p<0.05$. The fit of the final model was assessed using the Hosmer-Lemeshow test and the predictive ability was assessed using the receiver operating characteristic curve [63].

\section{Conclusions}

This is the first comprehensive study to investigate antimicrobial resistance and risk factors associated with Staphylococcus spp. colonization in healthy and diseased cats admitted to a veterinary clinic in Saudi Arabia. Staphylococcus spp. were isolated from $38.3 \%$ of the cats, and CoPS (S. aureus) were the most commonly isolated species in both healthy and diseased cats. The threat of MDR staphylococci is steadily increasing in Saudi Arabia. Our results show that MDR and MRS were common in both healthy and diseased cats, highlighting the importance of monitoring antimicrobial use and resistance in pets. The isolation of MRSA-ST80 from cats belonging to community-associated clonal lineages emphasizes the cross-transmission of MRSA between cats and humans. An effective antimicrobial stewardship program and further studies using a One Health approach may be required to investigate the role of cats as vectors for transmission of antimicrobial resistance to humans.

Supplementary Materials: The following are available online at https://www.mdpi.com/article/10 .3390/antibiotics10040367/s1, Table S1: Description and categories of the collected variables. Table S2. Description and categories of the collected variables.

Author Contributions: Conceptualization, A.E., I.E., and M.F.; methodology, A.E., I.E., and M.F.; software, A.E. and I.E.; validation, A.E., I.E., and M.F.; formal analysis, A.E. and I.E.; investigation, M.A. (Mohammed Alorabi), T.A.-M., A.A. (Ali Aldoweriej), A.A. (Abdullah Almubarak), and F.A.A.; resources, M.A. (Mohammed Alorabi), T.A.-M., A.A. (Ali Aldoweriej), A.A. (Abdullah Almubarak), and F.A.A.; data curation, M.A. (Mohammed Alorabi), T.A.-M., A.A. (Ali Aldoweriej), A.A. (Abdullah Almubarak), and F.A.A.; writing—original draft preparation, A.E., I.E., and M.F.; writing—review and editing, A.E., I.E., and M.F.; visualization, A.E. and I.E; supervision, M.F.; project administration, M.A. (Mohamed Alkafafy); funding acquisition, M.A. (Mohamed Alkafafy). All authors have read and agreed to the published version of the manuscript.

Funding: Taif University Researchers Supporting Project number (TURSP-2020/57), Taif University, P.O. Box 11099, Taif 21944, Saudi Arabia.

Institutional Review Board Statement: The Taif University Ethics Committee has approved the study protocol (TURSP-2020-57).

Informed Consent Statement: Not applicable.

Data Availability Statement: The data presented in this study are available on request from the corresponding author.

Acknowledgments: Authors thank Taif University Researchers Supporting Program (Project number: TURSP-2020/57), Taif University, Saudi Arabia for their support.

Conflicts of Interest: The authors declare no conflict of interest.

\section{References}

1. Nagase, N.; Sasaki, A.; Yamashita, K.; Shimizu, A.; Wakita, Y.; Kitai, S.; Kawano, J. Isolation and species distribution of staphylococci from animal and human skin. J. Vet. Med. Sci. 2002, 64, 245-250. [CrossRef] [PubMed]

2. Wertheim, H.F.; Melles, D.C.; Vos, M.C.; van Leeuwen, W.; van Belkum, A.; Verbrugh, H.A.; Nouwen, J.L. The role of nasal carriage in Staphylococcus aureus infections. Lancet Infect. Dis. 2005, 5, 751-762. [CrossRef]

3. Worthing, K.A.; Abraham, S.; Pang, S.; Coombs, G.W.; Saputra, S.; Jordan, D.; Wong, H.S.; Abraham, R.J.; Trott, D.J.; Norris, J.M. Molecular characterization of methicillin-resistant Staphylococcus aureus isolated from Australian animals and veterinarians. Microb. Drug Resist. 2018, 24, 203-212. [CrossRef] 
4. Becker, K.; Heilmann, C.; Peters, G. Coagulase-negative staphylococci. Clin. Microbiol. Rev. 2014, 27, 870-926. [CrossRef] [PubMed]

5. Huebner, J.; Goldmann, D.A. Coagulase-negative staphylococci: Role as pathogens. Annu. Rev. Med. 1999, 50, 223-236. [CrossRef] [PubMed]

6. May, L.; Klein, E.Y.; Rothman, R.E.; Laxminarayan, R. Trends in antibiotic resistance in coagulase-negative staphylococci in the United States, 1999 to 2012. Antimicrob. Agents Chemother. 2014, 58, 1404-1409. [CrossRef] [PubMed]

7. Buckland, E.L.; O'Neill, D.; Summers, J.; Mateus, A.; Church, D.; Redmond, L.; Brodbelt, D. Characterisation of antimicrobial usage in cats and dogs attending UK primary care companion animal veterinary practices. Vet. Rec. 2016, 179, 489. [CrossRef] [PubMed]

8. Loeffler, A.; Linek, M.; Moodley, A.; Guardabassi, L.; Sung, J.M.; Winkler, M.; Weiss, R.; Lloyd, D.H. First report of multiresistant, mecA-positive Staphylococcus intermedius in Europe: 12 cases from a veterinary dermatology referral clinic in Germany. Vet. Dermatol. 2007, 18, 412-421. [CrossRef] [PubMed]

9. Ross Fitzgerald, J. The Staphylococcus intermedius group of bacterial pathogens: Species re-classification, pathogenesis and the emergence of meticillin resistance. Vet. Dermatol. 2009, 20, 490-495. [CrossRef] [PubMed]

10. Damborg, P.; Broens, E.M.; Chomel, B.B.; Guenther, S.; Pasmans, F.; Wagenaar, J.A.; Weese, J.S.; Wieler, L.H.; Windahl, U.; Vanrompay, D. Bacterial zoonoses transmitted by household pets: State-of-the-art and future perspectives for targeted research and policy actions. J. Comp. Pathol. 2016, 155, S27-S40. [CrossRef]

11. Guardabassi, L.; Schwarz, S.; Lloyd, D.H. Pet animals as reservoirs of antimicrobial-resistant bacteria. J. Antimicrob. Chemother. 2004, 54, 321-332. [CrossRef]

12. Wieler, L.H.; Ewers, C.; Guenther, S.; Walther, B.; Lübke-Becker, A. Methicillin-resistant staphylococci (MRS) and extendedspectrum beta-lactamases (ESBL)-producing Enterobacteriaceae in companion animals: Nosocomial infections as one reason for the rising prevalence of these potential zoonotic pathogens in clinical samples. Int. J. Med. Microbiol. 2011, 301, 635-641. [PubMed]

13. Ewers, C.; Bethe, A.; Semmler, T.; Guenther, S.; Wieler, L. Extended-spectrum $\beta$-lactamase-producing and AmpC-producing Escherichia coli from livestock and companion animals, and their putative impact on public health: A global perspective. Clin. Microbiol. Infect. 2012, 18, 646-655. [CrossRef]

14. Harrison, E.M.; Weinert, L.A.; Holden, M.T.; Welch, J.J.; Wilson, K.; Morgan, F.J.; Harris, S.R.; Loeffler, A.; Boag, A.K.; Peacock, S.J. A shared population of epidemic methicillin-resistant Staphylococcus aureus 15 circulates in humans and companion animals. MBio 2014, 5. [CrossRef] [PubMed]

15. Loeffler, A.; Pfeiffer, D.; Lloyd, D.; Smith, H.; Soares-Magalhaes, R.; Lindsay, J. Meticillin-resistant Staphylococcus aureus carriage in UK veterinary staff and owners of infected pets: New risk groups. J. Hosp. Infect. 2010, 74, 282-288. [CrossRef] [PubMed]

16. Manian, F.A. Asymptomatic nasal carriage of mupirocin-resistant, methicillin-resistant Staphylococcus aureus (MRSA) in a pet dog associated with MRSA infection in household contacts. Clin. Infect. Dis. 2003, 36, e26-e28. [CrossRef] [PubMed]

17. Worthing, K.A.; Brown, J.; Gerber, L.; Trott, D.J.; Abraham, S.; Norris, J.M. Methicillin-resistant staphylococci amongst veterinary personnel, personnel-owned pets, patients and the hospital environment of two small animal veterinary hospitals. Vet. Microbiol. 2018, 223, 79-85. [CrossRef] [PubMed]

18. Committee for Medicinal Products for Human Use. European Medicines Agency Committee for Medicinal Products for Human Use (CHMP) Guideline on the Evaluation of Anticancer Medicinal Products in Man; European Medicines Agency: London, UK, 2006.

19. Gandolfi-Decristophoris, P.; Regula, G.; Petrini, O.; Zinsstag, J.; Schelling, E. Prevalence and risk factors for carriage of multi-drug resistant Staphylococci in healthy cats and dogs. J. Vet. Sci. 2013, 14, 449-456. [CrossRef]

20. Kaspar, U.; von Lützau, A.; Schlattmann, A.; Roesler, U.; Köck, R.; Becker, K. Zoonotic multidrug-resistant microorganisms among small companion animals in Germany. PLoS ONE 2018, 13, e0208364. [CrossRef]

21. Gómez-Sanz, E.; Ceballos, S.; Ruiz-Ripa, L.; Zarazaga, M.; Torres, C. Clonally diverse methicillin and multidrug resistant coagulase negative staphylococci are ubiquitous and pose transfer ability between pets and their owners. Front. Microbiol. 2019, 10, 485. [CrossRef]

22. Alzohairy, M.A. Colonization and antibiotic susceptibility pattern of methicillin resistance Staphylococcus aureus (MRSA) among farm animals in Saudi Arabia. Afr. J. Bacteriol. Res. 2011, 3, 63-68.

23. El-Deeb, W.; Fayez, M.; Elmoslemany, A.; Kandeel, M.; Zidan, K. Methicillin resistant Staphylococcus aureus among goat farms in Eastern province, Saudi Arabia: Prevalence and risk factors. Prev. Vet. Med. 2018, 156, 84-90. [CrossRef] [PubMed]

24. El-Ghareeb, W.R.; Almathen, F.S.; Fayez, M.M.; Alsultan, R.A. Methicillin resistant Staphylococcus aureus (MRSA) in camel meat: Prevalence and antibiotic susceptibility. Slov. Vet. Res. 2019, 56, 249-256. [CrossRef]

25. Older, C.E.; Diesel, A.; Patterson, A.P.; Meason-Smith, C.; Johnson, T.J.; Mansell, J.; Suchodolski, J.S.; Rodrigues Hoffmann, A. The feline skin microbiota: The bacteria inhabiting the skin of healthy and allergic cats. PLoS ONE 2017, 12, e0178555. [CrossRef] [PubMed]

26. Bierowiec, K.; Korzeniowska-Kowal, A.; Wzorek, A.; Rypuła, K.; Gamian, A. Prevalence of Staphylococcus species colonization in healthy and sick cats. Biomed Res. Int. 2019, 2019, 4360525. [CrossRef] [PubMed]

27. Windahl, U.; Bengtsson, B.; Nyman, A.-K.; Holst, B.S. The distribution of pathogens and their antimicrobial susceptibility patterns among canine surgical wound infections in Sweden in relation to different risk factors. Acta Vet. Scand. 2015, 57, 11. [CrossRef] [PubMed] 
28. Awosile, B.B.; McClure, J.T.; Saab, M.E.; Heider, L.C. Antimicrobial resistance in bacteria isolated from cats and dogs from the Atlantic Provinces, Canada from 1994-2013. Can. Vet. J. 2018, 59, 885. [PubMed]

29. Hauschild, T.; Wojcik, A. Species distribution and properties of staphylococci from canine dermatitis. Res. Vet. Sci. 2007, 82, 1-6. [CrossRef] [PubMed]

30. Jung, W.K.; Shin, S.; Park, Y.K.; Noh, S.M.; Shin, S.R.; Yoo, H.S.; Park, S.C.; Park, Y.H.; Park, K.T. Distribution and antimicrobial resistance profiles of bacterial species in stray dogs, hospital-admitted dogs, and veterinary staff in South Korea. Prev. Vet. Med. 2020, 184, 105151. [CrossRef] [PubMed]

31. Lane, M.J.; Roy, A.F.; Kearney, M.T.; Pucheu-Haston, C.M. Characterization, distribution, antimicrobial resistance and resistance risk factors in staphylococci isolated from cats from 2001 to 2014. Vet. Med. Sci. 2018, 4, 315-325. [CrossRef] [PubMed]

32. Loncaric, I.; Tichy, A.; Handler, S.; Szostak, M.P.; Tickert, M.; Diab-Elschahawi, M.; Spergser, J.; Künzel, F. Prevalence of methicillinresistant Staphylococcus sp.(MRS) in different companion animals and determination of risk factors for colonization with MRS. Antibiotics 2019, 8, 36. [CrossRef] [PubMed]

33. Bierowiec, K.; Płoneczka-Janeczko, K.; Rypuła, K. Is the colonisation of Staphylococcus aureus in pets associated with their close contact with owners? PLoS ONE 2016, 11, e0156052. [CrossRef] [PubMed]

34. Holm, B.; Petersson, U.; Mörner, A.; Bergström, K.; Franklin, A.; Greko, C. Antimicrobial resistance in staphylococci from canine pyoderma: A prospective study of first-time and recurrent cases in Sweden. Vet. Rec. 2002, 151, 600-605. [CrossRef] [PubMed]

35. Fazakerley, J.; Nuttall, T.; Sales, D.; Schmidt, V.; Carter, S.D.; Hart, C.A.; McEwan, N.A. Staphylococcal colonization of mucosal and lesional skin sites in atopic and healthy dogs. Vet. Dermatol. 2009, 20, 179-184. [CrossRef] [PubMed]

36. Qekwana, D.N.; Sebola, D.; Oguttu, J.W. Antimicrobial resistance patterns of Staphylococcus species isolated from cats presented at a veterinary academic hospital in South Africa. BMC Vet. Res. 2017, 13, 286. [CrossRef] [PubMed]

37. Conner, J.G.; Smith, J.; Erol, E.; Locke, S.; Phillips, E.; Carter, C.N.; Odoi, A. Temporal trends and predictors of antimicrobial resistance among Staphylococcus spp. isolated from canine specimens submitted to a diagnostic laboratory. PLoS ONE 2018, 13, e0200719. [CrossRef] [PubMed]

38. Joosten, P.; Ceccarelli, D.; Odent, E.; Sarrazin, S.; Graveland, H.; Van Gompel, L.; Battisti, A.; Caprioli, A.; Franco, A.; Wagenaar, J.A. Antimicrobial usage and resistance in companion animals: A cross-sectional study in three European countries. Antibiotics 2020, 9, 87. [CrossRef] [PubMed]

39. Monecke, S.; Skakni, L.; Hasan, R.; Ruppelt, A.; Ghazal, S.S.; Hakawi, A.; Slickers, P.; Ehricht, R. Characterisation of MRSA strains isolated from patients in a hospital in Riyadh, Kingdom of Saudi Arabia. Bmc Microbiol. 2012, 12, 146. [CrossRef] [PubMed]

40. Alkharsah, K.R.; Rehman, S.; Alkhamis, F.; Alnimr, A.; Diab, A.; Al-Ali, A.K. Comparative and molecular analysis of MRSA isolates from infection sites and carrier colonization sites. Ann. Clin. Microbiol. Antimicrob. 2018, 17, 7. [CrossRef]

41. Drougka, E.; Foka, A.; Koutinas, C.K.; Jelastopulu, E.; Giormezis, N.; Farmaki, O.; Sarrou, S.; Anastassiou, E.D.; Petinaki, E.; Spiliopoulou, I. Interspecies spread of Staphylococcus aureus clones among companion animals and human close contacts in a veterinary teaching hospital. A cross-sectional study in Greece. Prev. Vet. Med. 2016, 126, 190-198. [CrossRef] [PubMed]

42. Mairi, A.; Touati, A.; Lavigne, J.-P. Methicillin-Resistant Staphylococcus aureus ST80 Clone: A Systematic Review. Toxins 2020, 12, 119. [CrossRef] [PubMed]

43. Chongtrakool, P.; Ito, T.; Ma, X.X.; Kondo, Y.; Trakulsomboon, S.; Tiensasitorn, C.; Jamklang, M.; Chavalit, T.; Song, J.-H.; Hiramatsu, K. Staphylococcal cassette chromosome mec (SCCmec) typing of methicillin-resistant Staphylococcus aureus strains isolated in 11 Asian countries: A proposal for a new nomenclature for SCCmec elements. Antimicrob. Agents Chemother. 2006, 50, 1001-1012. [CrossRef] [PubMed]

44. Cîrlan, M.; Saad, M.; Coman, G.; Bilal, N.E.; Elbashier, A.M.; Kreft, D.; Snijders, S.; Van Leeuwen, W.; Van Belkum, A. International spread of major clones of methicillin resistant Staphylococcus aureus: Nosocomial endemicity of multi locus sequence type 239 in Saudi Arabia and Romania. Infect. Genet. Evol. 2005, 5, 335-339. [CrossRef] [PubMed]

45. Deurenberg, R.; Kalenic, S.; Friedrich, A.; Van Tiel, F.; Stobberingh, E. Molecular epidemiology of methicillin-resistant Staphylococcus aureus. Commun. Curr. Res. Educ. Top. Trends Appl. Microbiol. 2007, 1, 766-777.

46. Lina, G.; Piémont, Y.; Godail-Gamot, F.; Bes, M.; Peter, M.-O.; Gauduchon, V.; Vandenesch, F.; Etienne, J. Involvement of Panton-Valentine leukocidin—producing Staphylococcus aureus in primary skin infections and pneumonia. Clin. Infect. Dis. 1999, 29, 1128-1132. [CrossRef] [PubMed]

47. Vincze, S.; Brandenburg, A.G.; Espelage, W.; Stamm, I.; Wieler, L.H.; Kopp, P.A.; Lübke-Becker, A.; Walther, B. Risk factors for MRSA infection in companion animals: Results from a case-control study within Germany. Int. J. Med. Microbiol. 2014, 304, 787-793. [CrossRef]

48. Hogan, P.G.; Mork, R.L.; Boyle, M.G.; Muenks, C.E.; Morelli, J.J.; Thompson, R.M.; Sullivan, M.L.; Gehlert, S.J.; Merlo, J.R.; McKenzie, M.G. Interplay of personal, pet, and environmental colonization in households affected by community-associated methicillin-resistant Staphylococcus aureus. J. Infect. 2019, 78, 200-207. [CrossRef]

49. Weese, J.S.; Lefebvre, S.L. Risk factors for methicillin-resistant Staphylococcus aureus colonization in horses admitted to a veterinary teaching hospital. Can. Vet. J. 2007, 48, 921. [PubMed]

50. Magalhães, R.J.S.; Loeffler, A.; Lindsay, J.; Rich, M.; Roberts, L.; Smith, H.; Lloyd, D.H.; Pfeiffer, D.U. Risk factors for methicillinresistant Staphylococcus aureus (MRSA) infection in dogs and cats: A case-control study. Vet. Res. 2010, 41, 55. [CrossRef] [PubMed] 
51. Jaffe, R.I.; Lane, J.D.; Albury, S.V.; Niemeyer, D.M. Rapid extraction from and direct identification in clinical samples of methicillinresistant staphylococci using the PCR. J. Clin. Microbiol. 2000, 38, 3407-3412. [CrossRef] [PubMed]

52. Clinical and Laboratory Standards Institute (CLSI). Performance Standards for Antimicrobial Susceptibility Testing; Thirtieth CLSI Supplement M100-S30; CLSI: Wayne, PA, USA, 2020.

53. European Committee on Antimicrobial Susceptibility Testing, Breakpoint Tables for Interpretation of MICs and Zone Diameters, (Version 11.0). 2021. Available online: https://www.eucast.org/clinical_breakpoints/ (accessed on 15 January 2021).

54. Magiorakos, A.-P.; Srinivasan, A.; Carey, R.B.; Carmeli, Y.; Falagas, M.E.; Giske, C.G.; Harbarth, S.; Hindler, J.F.; Kahlmeter, G.; Olsson-Liljequist, B.; et al. Multidrug-resistant, extensively drug-resistant and pandrug-resistant bacteria: An international expert proposal for interim standard definitions for acquired resistance. Clin. Microbiol. Infect. 2012, 18, 268-281. [CrossRef] [PubMed]

55. Krumperman, P.H. Multiple antibiotic resistance indexing of Escherichia coli to identify high-risk sources of fecal contamination of foods. Appl. Environ. Microbiol. 1983, 46, 165-170. [CrossRef] [PubMed]

56. Murakami, K.; Minamide, W.; Wada, K.; Nakamura, E.; Teraoka, H.; Watanabe, S. Identification of methicillin-resistant strains of staphylococci by polymerase chain reaction. J. Clin. Microbiol. 1991, 29, 2240-2244. [CrossRef] [PubMed]

57. Enright, M.C.; Day, N.P.; Davies, C.E.; Peacock, S.J.; Spratt, B.G. Multilocus sequence typing for characterization of methicillinresistant and methicillin-susceptible clones of Staphylococcus aureus. J. Clin. Microbiol. 2000, 38, 1008-1015. [CrossRef] [PubMed]

58. Solyman, S.; Black, C.; Duim, B.; Perreten, V.; Van Duijkeren, E.; Wagenaar, J.; Eberlein, L.; Sadeghi, L.; Videla, R.; Bemis, D. Multilocus sequence typing for characterization of Staphylococcus pseudintermedius. J. Clin. Microbiol. 2013, 51, 306-310. [CrossRef] [PubMed]

59. Otokunefor, K.; Sloan, T.; Kearns, A.M.; James, R. Molecular characterization and Panton-Valentine leucocidin typing of community-acquired methicillin-sensitive Staphylococcus aureus clinical isolates. J. Clin. Microbiol. 2012, 50, 3069-3072. [CrossRef] [PubMed]

60. Gu, Z.; Eils, R.; Schlesner, M. Complex heatmaps reveal patterns and correlations in multidimensional genomic data. Bioinformatics 2016, 32, 2847-2849. [CrossRef] [PubMed]

61. Kruskal, J.B. Nonmetric multidimensional scaling: A numerical method. Psychometrika 1964, 29, 115-129. [CrossRef]

62. Anderson, M.J.; Walsh, D.C. PERMANOVA, ANOSIM, and the Mantel test in the face of heterogeneous dispersions: What null hypothesis are you testing? Ecol. Monogr. 2013, 83, 557-574. [CrossRef]

63. Dohoo, I.; Martin, S.; Stryhn, H. Veterinary Epidemiologic Research; VER. Inc.: Charlottetown, PE, Canada, 2009. 